\title{
CONCEITOS FUNDAMENTAIS DO SISTEMA DE PRECEDENTES E FUNDAMENTAÇÃO DAS DECISÕES \\ JUDICIAIS
}

\section{FUNDAMENTAL CONCEPTS OF THE PRECEDENTS SYSTEM AND JUDICIAL REASONING}

RESUMO: Estamos aplicando corretamente os precedentes? A compreensão da teoria dos precedentes exige que o estudioso conheça alguns conceitos fundamentais. As noções de ratio decidendi e obiter dictum são fundamentais. Da mesma forma, conhecer os conceitos de precedente, jurisprudência e súmula é necessário. Um ponto em comum entre todos esses elementos, é a necessidade de motivação das decisões judiciais. Sem uma decisão bem fundamentada, com respeito ao art. 93 , IX, da CR e ao art. $489, \S 1^{\circ}$, do $\mathrm{CPC}$, não há como trabalhar com precedentes como um sistema organizado. E o problema é visto em termos práticos, como no $\mathrm{CC} \mathrm{n}^{\circ} 144.922 / \mathrm{MG}$, especialmente em confronto com julgado posterior, que mal aplicou o precedente, demonstrando nosso apego à "cultura do ementário". Por isso, a fundamentação das decisões, em sua dimensão interna e externa, é um ponto chave, indispensável à boa aplicação dos precedentes judiciais.

Palavras-chave: Precedentes. Cultura do Ementário. Fundamentação das decisões.

ABSTRACT: Are we applying the precedents correctly? To Understand the precedents as theory, it is required that the scholar knows some fundamental concepts. The ideas of ratio decidendi and obiter dictum are fundamental. Likewise, knowing the definition of precedent, jurisprudence and summary pronouncement is necessary. One point in common among all these elements, is the need to judicial reasoning. Without a well-reasoned decision, with respect to art. 93, IX, CR and art. $489, \S 1^{\circ}$, of the CPC, there is no way to work with precedents as a organized system. And the problem is seen in practical terms, as in $\mathrm{CC}{ }^{\circ} 144.922 / \mathrm{MG}$, especially when we face it with other cases that make incorrect use of the precedent, showing our attachment to the "ementary culture". For this reason, the judicial reasoning, in internal and external dimension, is a key point, indispensable for the proper application of judicial precedents.

Keywords: Precedents. Ementary Culture. Judicial Reasoning.

\section{GENERALIDADES}

${ }^{1}$ Bacharel e Mestre em Direito pela Universidade Federal de Pernambuco. Doutorando pela Universidade Federal da Bahia. Membro da ANNEP e do IBDP. Procurador da Fazenda Nacional. 
A decisão judicial é um texto jurídico. De sua interpretação resultam ao menos duas normas, uma individual, outra geral. A norma jurídica individualizada regula o caso concreto submetido ao órgão julgador é extraída a partir dispositivo da sentença. Já a norma jurídica geral é produzida pela jurisdição através de um processo indutivo - o juiz examina um caso e generaliza a sua solução. A partir de um problema concreto surge uma solução aplicável a uma generalidade de casos futuro semelhantes.

$\mathrm{O}$ processo, portanto, funciona ele mesmo como fonte de norma. $\mathrm{O}$ procedimento em contraditório reestrutura a ordem jurídica em uma função que o legislador não pode (ou ao menos, não deve) cumprir. As normas decorrentes do processo legislativo se dedicam eminentemente a um juízo prospectivo: regular fatos futuros e eventuais. Não é o que se dá com o processo.

As normas decorrentes do processo - como procedimento em contraditório - $\mathrm{a}$ isto não se limitam. E, para compreensão do processo como fonte de norma, é de suma importância avaliar se estamos trabalhando bem com um sistema de precedentes, especialmente após o advento do CPC/15. É a este estudo que nos dedicamos aqui. Estamos aplicando bem os precedentes?

Nosso caminho parte de alguns conceitos básicos de teoria dos precedentes judiciais; passa pela análise do relevante julgamento do $\mathrm{CC} \mathrm{n}^{\circ}$ 144.922/MG, com especial recorte daquilo que chamamos de cultura do ementário; finaliza na tentativa de demonstrar a íntima relação dos temas com o dever de fundamentação das decisões. Sigamos.

\section{RATIO DECIDENDI E OBITER DICTUM}

O precedente é a decisão judicial cujo núcleo essencial pode servir de diretriz para julgamento futuro de caso análogo. Nada obstante a referência seja à eficácia persuasiva do precedente, esse caráter é da sua razão de decidir ${ }^{2}$ ou ratio decidendi ou, como preferem os americanos, a holding.

\footnotetext{
${ }^{2}$ É preciso fazer uma ressalva. O termo razão de decidir é adotado, no Brasil - muito comumente - como substitutivo de ratio decidendi. Não se trata, todavia, de sinônimo. É que a ratio decidendi vai muito além das razões que o judiciário tomou para decidir. A ratio decidendi, como será desenvolvido adiante, está no plano normativo, trata-se mesmo da norma geral construída jurisprudencialmente, seria o mesmo que a identificação das razões para a tomada de decisão (=reason for the decision). Por outro lado, a razão de decidir (=judicial reasoning) é elemento textual. Trata-se, pois, das razões trazidas à baila pelo julgado no texto da decisão. Dela podem ser extraídas a ratio e também o obiter dictum. Veja-se: "Ratio decidendi can mean either 'reason for the decision' or 'reason for deciding'. It should not be inferred from this that the ratio decidendi of a case must be the judicial reasoning Judicial reasoning may be integral to the ratio, but the ratio itself is more than the reasoning, and within many cases there will be judicial reasoning that constitutes not part of the ratio, but obiter dicta" (DUXBURY, 2008, p. 67-68) Em tradução livre: "Ratio decidendi pode significar tanto 'razão para decisão' quanto 'fundamentação da decisão'. Não se deve inferior disso que a ratio decidendi de um caso seja a fundamentação da decisão. A fundamentação da
} 
É a tese jurídica consignada na decisão, extraída de sua interpretação, com base na qual se decide o caso em análise. A ratio decidendi se identifica não com a decisão do caso concreto (não está contida no dispositivo), mas com as razões jurídicas que fundamentaram a tomada daquela decisão (CUNHA, 2012) ${ }^{3}$; conforma uma tese jurídica geral acolhida pelo julgador, capaz de desprender-se do incidente para ser aplicada a outras situações análogas, ainda que decorra de raciocínio indutivo.

O precedente é uma decisão que precede outras. A ratio decidendi é a norma extraída daquela decisão. Nada obstante, é comum a utilização dos termos em metonímia.

Gustavo Santana Nogueira (2012, p. 182) explica, tratando dos precedentes vinculantes (ainda que a lição possa ser apreendida no estudo destes e também dos precedentes persuasivos):

Só se pode falar em adesão aos precedentes a partir do momento em que se separam duas partes fundamentais de uma decisão judicial: a ratio decidendi (literalmente, razões de decidir) e a obiter dictum (literalmente, dito para morrer). É costume afirmar que em uma decisão judicial apenas a ratio decidendi vincula, e não a obiter dictum, ou dicta, no plural.

A norma jurídica geral que serve como padrão decisório para casos futuros semelhantes é a ratio decidendi. Quando um precedente é reiteradamente aplicado em um juízo, há a formação da jurisprudência. Tornando-se dominante aquele entendimento, podem os tribunais editar enunciados de súmula, transformando em texto a norma geral construída jurisprudencialmente (MENDES; COELHO; BRANCO, 2007, p. 914-917) ${ }^{4}$. O entendimento jurisprudencial é a norma. $\mathrm{O}$ enunciado de súmula é o texto da norma, é o seu enunciado.

Com o respeito aos precedentes ou - como originalmente denomina-se na tradição da common law - ao stare decisis a resposta do judiciário às questões postas em juízo torna-se mais previsível, o que possibilita o aumento da confiança depositada no Judiciário, preservando a sua legitimidade (MACEDO; PEREIRA; PEIXOTO, 2012, p. 530).

decisão pode integrar a ratio, mas a ratio em si é mais que fundamentação, e em vários casos haverá fundamentação da decisão que constitui não parte da ratio, mas das obiter dicta". Neste excerto, todavia, utilizaremos os termos como sinônimos, em razão mesmo de que os escritos de língua português a respeito do tema parecem consagrar esa relação.

${ }^{3}$ Afirma-lo, não implica dizer que a ratio está no trecho "fundamentação" da decisão. Perceba-se: o precedente é elemento textual. Suas subdivisões (fatos, fundamentos e dispositivo) são, portanto, texto. A norma geral extraída do precedente, todavia, está no plano normativo. Inclusive, a enorme importância que adquire a análise da situação de fato para a futura aplicação da ratio decidendi demonstra que ela (norma no plano do pensamento) não está na fundamentação (plano textual da decisão). Nesse mesmo sentido, anota Lucas Buril (2016, p. 239). ${ }^{4}$ Ainda, a técnica da criação de enunciados sumulados é um dos desdobramentos do processo de abstrativização das decisões judiciais. Ganha destaque na abstrativização do controle difuso de constitucionalidade pelo STF, ao lado de outras técnicas, como a da repercussão geral. 
O obiter dictum ou, no plural, obiter dicta, por outro lado, são os fundamentos "prescindíveis para o alcance do resultado fixado" no dispositivo da decisão - utilizando dos termos do art. $521, \S 4^{\circ}$, I, do então projeto de CPC, que acabou por não prevalecer na redação final da lei ${ }^{\circ} 13.105 / 2015$. É que, se a ratio decidendi é o fundamento jurídico do qual decorre a decisão, o obiter dictum é fundamento acessório, dispensável, sem influência substancial na caracterização daquela situação específica. É o fundamento que serve de suporte à construção do raciocínio que leva à decisão, conquanto não seja necessário.

O obiter dictum na decisão é encontrado de forma negativa, por exclusão. Assim, todos os fundamentos indispensáveis à formação da tese jurídica, são ratio decidendi. Tudo aquilo que for prescindível para a tomada da decisão, é obiter dictum. Nesse sentido, "os pronunciamentos que digam respeito a pedido não formulado e a causa de pedir não invocada são, inegavelmente, obiter dicta" (MARINONI, 2012, p. 623).

Não é possível apontar, todavia, uma técnica definitiva para, no caso concreto, extrair da ratio decidendi do precedente. Trata-se o tema, inclusive, de um dos grandes problemas enfrentados pelos juristas do common law. Na linha do que foi apresentado, talvez a mais tradicional proposição de técnica para a identificação da ratio seja a proposta por Eugene Wambaugh. O autor propõe um método de exclusão a partir do confronto dos fundamentos do precedente com uma proposição contrária àquela que se imagina seja a ratio. $\mathrm{O}$ resultado desse confronto demonstraria o seguinte: i) caso a aplicação da tese contrária não fosse apta a alterar o resultado do julgamento, estar-se-ia diante de obiter dictum; ii) caso a aplicação da tese contrária implicasse alteração na conclusão do julgamento, significaria que ali estava a ratio decidendi, tese central utilizada para a tomada de decisão (WAMBAUGH, 1892, p. 5-6).

Outra técnica bastante referenciada pela doutrina é aquela apresentada por Arthur L. Goodhart. Para o autor, cujo método nomeia de principle of the case ("princípio do caso" em tradução livre), é de suma importância para a identificação da ratio decidendi definir quais os fatos materiais (material facts) nos quais o magistrado se baseou para a tomada de decisão. Esse seria o contexto fático no qual o precedente se formaria. Assim, para considerar a razão de decidir, aplicando-a a caso futuro e análogo, impõe-se considerar apenas tais fatos matérias - ou poderíamos dizer, imprescindíveis - indispensáveis à toma de decisão. Fatos tidos por 
hipotéticos ou que não possuíssem qualquer relação mesmo com a tomada de decisão, seriam relacionados ao obiter dictum (GOODHART, 1930, p. 161-183) ${ }^{5}$.

Contudo, a separação entre obiter dictum e ratio decidendi muitas vezes não é clara no caso concreto, especialmente quando o intérprete se depara com decisões cujas razões de decidir são múltiplas. Tanto um quanto outro estão presentes na fundamentação da decisão, não havendo uma cisão precisa do que é um ou outro. De fato, o obiter dictum tem sua importância porque pode ser levado em conta nas razões do recurso à decisão ou pode até sinalizar o entendimento do órgão julgador a respeito de outras questões que apesar de não debatidas naquele caso específico, podem ser objeto central de outra discussão.

Neste último ponto reside uma situação importante: quando se fala de eficácia do precedente (vinculante ou persuasiva), refere-se (como já apontado) à ratio decidendi e, por consequência, não ao obiter dictum. O problema é saber, no caso concreto o que realmente abarca a regra geral e o que foi posto como comentário paralelo. Nesse processo, muitas vezes se faz menção ao obiter dictum como se ratio decidendi fosse, e vice-versa. Decorre, como parece claro, de um erro de técnica do julgador e do intérprete (sem levar em conta eventual intenção para fazê-lo), na medida em que não procede uma boa verificação do caso que está mencionando como precedente em sua decisão.

Todo o problema é que o estudo dos precedentes é feito visando à estabilidade do sistema e à proteção das expectativas, posto que essa confusão em delimitar o que é obiter dictum e o que é ratio decidendi significa um sopro de insegurança em um ambiente que busca exatamente a segurança jurídica e o tratamento isonômico no processo.

\section{PRECEDENTE, JURISPRUDÊNCIA E SÚMULA}

A compreensão de alguns conceitos é indispensável para o estudo do tema em análise. É preciso compreender com clareza a diferença entre precedente, jurisprudência e súmula.

\footnotetext{
${ }^{5}$ Disponível em: http://www.jstor.org/stable/790205. Acesso: 09/09/2020. Especialmente o seguinte trecho (p. 169), em que o próprio autor reconhece a dificuldade da empreitada: "The first and most essential step in the determination of the principle of a case is, therefore, to ascertain the material facts on which the judge has based his conclusion. Are there any rules which will help us in isolating these material facts? It is obvious that none can be found which will invariably give us the desired result, for if this were possible then the interpretation of cases, which is one of the most difficult of the arts, would be comparatively easy." Em tradução livre: "O primeiro e mais essencial passo na definição do princípio do caso é, portanto, acertar os fatos materiais em que o juiz se baseou para chegar à conclusão. Haverá alguma regra que nos auxilie em isolar esses fatos materiais? É óbvio que nenhuma pode ser identificada para nos oferecer o resultado desejado, e se isso fosse possível então a interpretação dos casos, uma das partes mais difíceis da tarefa, seria comparativamente mais simples".
} 
De fato, todos os três conceitos são regidos pela necessidade de proteção às expectativas decorrentes da atuação dos tribunais. A garantia constitucional da segurança jurídica (art. $5^{\circ}$, caput) respeita não só à atuação do Legislativo, mas também do Judiciário, que desempenha atividade criadora de direito. Nesse sentido, Marinoni (2012, p. 559):

A segurança jurídica, vista como estabilidade e continuidade da ordem jurídica e previsibilidade das consequências jurídicas de determinada conduta, é indispensável para a conformação de um Estado que pretenda ser 'Estado de Direito'.

O direito fundamental à segurança jurídica no processo é elemento indissociável da ideia de processo cooperativo e de formalismo-valorativo. $\mathrm{O}$ ambiente de diálogo que o processo proporciona, implica necessariamente a proteção contra ausência de previsibilidade da atuação judicial.

$\mathrm{O}$ direito à segurança jurídica no processo constitui direito à certeza, à estabilidade, à confiabilidade e à efetividade das situações jurídicas processuais. Ainda, a segurança jurídica determina não só segurança no processo, mas também segurança pelo processo. (SARLET; MARINONI; MITIDIERO, 2012, p. 671)

Demonstrada a importância da questão, passemos a análise pormenorizada dos institutos.

“O precedente nada mais é do que uma decisão judicial, que tem relação de anterioridade a outras, servindo-lhes de premissa" (CUNHA, 2012, p. 356). O precedente é a decisão de um caso concreto que apresenta em seu núcleo uma norma jurídica formada através de um processo indutivo, apta à utilização em casos análogos posteriores. É, pois, uma decisão passada (=precedente) aplicável a caso análogo presente. Perceba-se, nesse sentido, que se trata de conceito relacional, pois só há caso futuro se houver caso precedente. Lucas Buril (2016, p. 70) acerta com precisão:

Nesse sentido, o precedente judicial abarca toda a decisão - relatório, fundamentos e dispositivo -, não discriminando as parcelas mais importantes para a concretização do direito. Precedente, aqui, é o mesmo que "decisão precedente" e tem inegável aspecto relacional, na medida em que só pode ser aplicado quando há casos análogos.

Cruz e Tucci (2004, p. 12), em passagem por muitos referida, esclarece:

(...) todo precedente é composto de duas partes distintas: $a$ ) as circunstâncias de fato que embasam a controvérsia; e $b$ ) a tese ou o princípio jurídico assentado na motivação (ratio decidendi) do provimento decisório.

De observar, então, que o precedente em si, como decisão jurídica, não tem como corolário a atribuição de efeito vinculante. $\mathrm{O}$ fato de trazer como elemento uma tese ou princípio jurídico construído pela análise do caso concreto, não significa que deva ser obrigatoriamente 
observado em casos análogos futuros - isso se dá pelo stare decisis ou pela eficácia vinculante. Nada obstante, não se pode deixar de reconhecer que apesar de muitas vezes se falar em efeito vinculante do procedente, em verdade se está a referir a sua ratio decidendi, que é elemento, mas não o precedente propriamente dito.

O precedente não é, contudo, toda e qualquer decisão. Só é precedente a decisão judicial que conforma o posicionamento a respeito de determinada questão de direito ali discutida, induzindo uma norma geral, apta a ser aplicada em casos semelhantes. Decisão somente sobre matéria de fato não é precedente, assim como a decisão que se fundamente em texto expresso de lei ou em outro precedente, também não é. "Em suma, é possível dizer que o precedente é a primeira decisão que elabora a tese jurídica ou é a decisão que definitivamente a delineia, deixando-a cristalina" (MARINONI, 2010, p. 218).

Passando ao tratamento da jurisprudência, interessante notar que a distinção é meramente quantitativa. A jurisprudência representa a consolidação do entendimento de um órgão julgador a respeito de determinada matéria, através da reiteração de julgados no mesmo sentido (=multiplicidade de julgamentos baseados em uma mesma ratio decidendi). Assim, partindo-se de um precedente, onde sua ratio decidendi é tomada como regra geral, caso venha encontrar aplicação em casos futuros análogos, a sucessão de julgados no mesmo sentido cria a jurisprudência (PEIXOTO, 2015, p. 159) ${ }^{6}$.

Valendo-se do que ensina Santos Justo (2008, p. 86) sobre a iurisprudentia no direito romano, mesmo reconhecendo as grandes diferenças na acepção que se tem do instituto hodiernamente, continua atual o entendimento de que à jurisprudência cabe "a função de revelar (interpretare), desenvolver e adaptar o direito às exigências de cada momento; (...) e o iuris prudens não é apenas o conhecedor, mas sobretudo o criador do direito". Revela-se, portanto, o caráter criativo da decisão judicial, elevando-se a jurisprudência ao status de fonte do direito (DIDIER; BRAGA; OLIVEIRA, 2014, p. 391), como hoje já se reconhece.

Heleno Taveira Torres (2011, p. 465) nos permite introduzir o tema das súmulas, ao mesmo tempo em que diferencia os institutos trabalhados:

\footnotetext{
${ }^{6}$ No mesmo sentido, Leonardo Carneiro da Cunha, que, valendo-se da doutrina italiana, aponta: "Michele Taruffo lembra que 'precedente e jurisprudência são termos frequentemente utilizados como se fossem sinônimos, mas existe entre eles uma nítida distinção. Há, antes de tudo, uma distinção de caráter quantitativo: quando se fala em precedente, refere-se somente a uma única decisão relativa a um caso particular, enquanto a alusão à jurisprudência indica a existência de uma pluralidade considerável de decisões relativas a vários e diversos casos concretos. A decisão que se assume com precedente é uma só. Diversamente, o que se chama de jurisprudência é a referência a muitas decisões"”. (CUNHA, 2012, p. 357).
} 
A relevância prática dos precedentes (decisões isoladas de tribunais), da consolidação da jurisprudência (conjunto de decisões) ou dos mecanismos de uniformização de jurisprudência (súmulas) tem como principal objetivo garantir a estabilidade das decisões, como forma de preservação da isonomia, especialmente nas questões de direito arguidas em processos semelhantes, e a observância dos seus conteúdos pelos órgãos de Estado. Como standard jurídico, a prevalência da jurisprudência assentada ou uniforme é um valor positivo para ordenamento.

A súmula, como já deixou transparecer pelo último excerto, é uma das técnicas de uniformização de jurisprudência que nosso ordenamento jurídico prevê. É um conjunto de enunciados que afirmam o entendimento de um determinado tribunal a respeito dos temas por ele decididos, onde cada enunciado espelha uma ratio decidendi (norma geral decorrente de um processo indutivo) que fundamenta uma jurisprudência pacífica ou dominante.

Assim, apesar de não se confundirem, precedente, jurisprudência e súmula estão relacionados em um processo evolutivo de desenvolvimento da norma jurídica construída a partir da jurisdição. "Um precedente, quando reiteradamente aplicado, se transforma em jurisprudência que, se predominar em tribunal, pode dar ensejo à edição de um enunciado na súmula da jurisprudência deste tribunal”(DIDIER; BRAGA; OLIVEIRA, 2014, p. 391).

Um grande problema na edição de enunciados de súmula é a atecnia dos julgadores para a redação do texto. É que o enunciado, ao refletir somente a regra geral, distancia-se do suporte fático que ensejou a conformação do precedente reiteradamente aplicado, e que veio a lhe dar origem. Para evitar a aplicação das súmulas em um contexto fático não coincidente, o ideal seria que não contivessem termos imprecisos, abertos ou conceitos jurídicos indeterminados e relacionassem a tese jurídica às circunstâncias fáticas que deram causa ao entendimento. Seria mesmo de se aplicar corretamente a norma do art. 926, $\S 2^{\circ}$ do CPC, ou seja, que ao editar enunciados de súmula, os tribunais se ativessem às circunstâncias fáticas dos precedentes que motivaram sua criação.

Se a ideia da súmula é exatamente afirmar o posicionamento contextualizado do tribunal sobre termos abertos decorrentes da atividade legislativa, não pode se aplicar a mesma técnica quando da edição dos enunciados.

Para que isso pudesse ocorrer (a consideração das circunstâncias do caso no texto sumulado) haveria de se ter a compreensão de que a súmula não constitui mero enunciado ou simples consolidação da interpretação da lei, mas algo que reflete uma tese jurídica inseparável das circunstâncias concretas que a motivaram. (MARINONI, 2010, p. 216)

Não é, contudo, o que se observa. Exemplo é o enunciado nº 11 da Súmula Vinculante, com a seguinte redação: 
Só é lícito o uso de algemas em casos de resistência e de fundado receio de fuga ou de perigo à integridade física própria ou alheia, por parte do preso ou de terceiros, justificada a excepcionalidade por escrito, sob pena de responsabilidade disciplinar, civil e penal do agente ou da autoridade e de nulidade da prisão ou do ato processual a que se refere, sem prejuízo da responsabilidade civil do estado. (grifamos)

Ora, o que se entende por "justificada excepcionalidade" e quem poderá dizer se houve ou não? É um enunciado de súmula com pouca ou nenhuma serventia, na medida em que não funciona como instrumento de segurança jurídica e previsibilidade das decisões. Será necessário, no caso concreto, interpretar o que é tal "justificada excepcionalidade", podendo um juiz de Olinda ter entendimento diverso de um juiz de Recife em face de casos bastante semelhantes. Assim, o enunciado pode levar à situação esdrúxula onde o mesmo texto fundamente, em casos análogos, tanto o legítimo uso de algemas, quanto a nulidade da prisão, pois incapaz de uniformizar a jurisprudência referente ao tema.

O "verbete já é o resultado de interpretações reiteradas do Tribunal"7, perdendo a sua razão de ser se, para sua aplicação, houver a necessidade de reavivar as discussões a respeito das razões de decidir que compõem os precedentes que lhe serviram de base.

Perceba-se: é sempre adequado o retorno aos casos que fundamentaram a construção do enunciado como forma de interpretar a aplicar a ratio. A interpretação é um processo necessário à aplicação de qualquer norma. O que não é adequado - especialmente quando decorre de uma má redação do enunciado (=texto) - é a necessidade de retorno em razão da porosidade dos termos utilizados. Uma redação mais adequada dos enunciados sumulares, evitando a utilização de conceitos indeterminados, facilita a interpretação e reduz a possibilidade de decisões contraditórias entre si fundamentadas - supostamente - na mesma norma.

\section{ATENTANDO A UM PROBLEMA: A CULTURA DO EMENTÁRIO E O CC} $n^{\circ} 144.922 / M G$

Não menos dificultosa é a interpretação e aplicação dos precedentes através da simples menção às ementas dos julgados. Tais excertos são um importante técnica para dar publicidade e facilitar a compreensão do entendimento firmado pelo tribunal. Trata-se de um pequeno texto redigido de forma objetiva, normalmente fixado no início do documento onde constam os relatórios e os votos e também antes das conclusões, onde são postas as principais informações sobre o julgamento: fatos relevantes e uma tentativa de enunciar a razão de decidir. Todavia, não se pode esquecer que "a norma do precedente é diferente do texto do precedente, sendo

${ }^{7}$ Nas palavras do então Ministro do STF Sepúlveda Pertence, no julgamento pelo Plenário da Corte no HC 85.185-1, DJ 01/09/2006. 
equivocado reduzi-la à fundamentação ou qualquer combinação de elementos da decisão do qual advém - da mesma forma que não se deve reduzir a norma legal ao texto da lei” (MACÊDO, 2016, p. 70).

$\mathrm{Na}$ prática forense, quando se deseja apontar ao julgador o entendimento firmado em casos anteriores, junta-se aos articulados a sua ementa, pois funciona como uma espécie de resumo do entendimento adotado. Todo acórdão conterá ementa (art. 943, § $1^{\circ}$ do CPC).

Ocorre que, talvez mesmo pela forte influência da cultura do civil law característica de nossa ordem jurídica, o processo civil no Brasil sofre com aquilo que chamo de cultura do ementário $^{8}$. Trata-se da aplicação descuidada de ementas, ou mesmo trechos delas, como se aptas a refletirem por si sós, compreensões consignadas nos julgamentos. As ementas são colacionadas em articulados sem maiores cuidados com a identificação do contexto fático que gerou o julgamento, fazendo com que muitas vezes os precedentes citados em nada se relacionem - e, portanto, a ratio decidendi não se aplique - ao julgamento do caso concreto. Trata-se de situação problemática para o desenvolvimento da cultura de precedentes no Brasil, pois a "aplicação dos precedentes não pode prescindir do inteiro teor dos julgados, em que se pode buscar efetivamente a norma, os fatos que lhe deram origem e mesmo divergências entre os votos" (PEIXOTO, 2015, p. 163).

Há um exemplo notório, resultado da ementa redigida para o CC $\mathrm{n}^{\circ} 144.922 / \mathrm{MG}$, proveniente da Primeira Seção do Superior Tribunal de Justiça. Trata-se do conflito de competência no caso do rompimento da barragem de Mariana em Minas Gerais.

O conflito de competência foi suscitado pela empresa Samarco Mineração S.A. "em decorrência da tramitação de ações civis públicas aforadas na Justiça Estadual [MPE] e na Justiça Federal $[\mathrm{MPF}]$ de Governador Valadares/MG, com o objetivo de determinar a distribuição de água mineral à população valadarense, em virtude da poluição do Rio Doce ocasionada com o rompimento da barragem de Fundão, em Mariana/MG”.

A problemática girou em torno da definição do juízo competente entre a $7^{\text {a }}$ Vara Cível da comarca de Governador Valadares/MG, a 2 ${ }^{\text {a }}$ Vara Federal na Subseção Judiciária de Governador Valadares/MG ou a 12a Vara Federal na Seção Judiciária de Belo Horizonte/MG. Dentre tantos outros temas dispostos na longa ementa do julgado, a respeito da definição de competência restou consignado o seguinte, in verbis (grifos no original):

\footnotetext{
${ }^{8}$ Nada obstante o fenômeno descrito se identifique com críticas feitas pela doutrina especializada, não foi encontramos referência expressa a este termo.
} 
(...) 17. Dessas circunstâncias, observa-se que a $12^{\mathrm{a}}$ Vara Federal da Secção Judiciária de Minas Gerais possui melhores condições de dirimir as controvérsias aqui postas, decorrentes do acidente ambiental de Mariana, pois além de ser a Capital de um dos Estados mais atingidos pela tragédia, já tem sob sua análise processos outros, visando não só a reparação ambiental stricto sensu, mas também a distribuição de água à população dos Municípios atingidos, entre outras providências, o que lhe propiciará, diante de uma visão macroscópica dos danos ocasionados pelo desastre ambiental do rompimento da barragem de Fundão e do conjunto de imposições judiciais já direcionadas à empresa Samarco, tomar medidas dotadas de mais efetividade, que não corram o risco de ser neutralizadas por outras decisões judiciais provenientes de juízos distintos, além de contemplar o maior número de atingidos.

\section{EXCEÇÕES À REGRA GERAL.}

18. Há que se ressalvar, no entanto, as situações que envolvam aspectos estritamente humanos e econômicos da tragédia (tais como o ressarcimento patrimonial e moral de vítimas e familiares, combate a abuso de preços etc) ou mesmo abastecimento de água potável que exija soluções peculiares ou locais, as quais poderão ser objeto de ações individuais ou coletivas, intentadas cada qual no foro de residência dos autores ou do dano. Nesses casos, devem ser levadas em conta as circunstâncias particulares e individualizadas, decorrentes do acidente ambiental, sempre com base na garantia de acesso facilitado ao Poder Judiciário e da tutela mais ampla e irrestrita possível. Em tais situações, o foro de Belo Horizonte não deverá prevalecer, pois significaria óbice à facilitação do acesso à justiça, marco fundante do microssistema da ação civil pública. (...)

Trocando em miúdos, face às circunstâncias do caso concreto, a corte entendeu que a competência para processar e julgar as demandas coletivas decorrentes do acidente ocorrido em Mariana era da 12a Vara Federal na Capital do Estado. Prevaleceu, no caso, o fato de que o juízo já estava processando tantas outras demandas relativas ao mesmo fato, permitindo uma "visão macroscópica do desastre". O grande problema é que o ponto seguinte (18) da ementa, traz a compreensão da Corte acerca de situações excepcionais e, portanto, ressalvadas da regra posta no ponto anterior (17). A depender da situação de fato, caso envolva aspectos exemplificados ali, a competência seria mesmo da Justiça Federal no foro de residência dos autores ou da ocorrência do dano. Inclusive, para excepcionar a regra geral, "devem ser levadas em conta as circunstâncias particulares e individualizadas", sempre com os olhos voltados ao amplo acesso à justiça.

Perceba-se: da ementa não se pode extrair ou compreender regra alguma. Não possui fundamentação suficiente para que se considere a decisão, no ponto, suficientemente motivada. Há claro ferimento ao art. $489, \S^{\circ}$, inciso III do CPC.

Foge ao objeto do presente trabalho uma análise aprofundada da questão de fundo do julgado em comento, referente à definição de competência nos termos do art. $2^{\circ}$, da Lei $n^{\circ}$ 7.347/85 (Lei da Ação Civil Pública). Não nos cabe, aqui, compreender ou criticar a decisão 
tomada. A ideia é apenas demonstrar quão importante é a compreensão dos conceitos fundamentais, temas basilares de teoria dos precedentes. Não estamos diante aqui de um tema novo na doutrina. Mas este julgamento deixa demonstra a necessidade de sempre a ele retornamos.

Em um exercício de retórica, caso fossem suprimidas as referências aos juízos em conflito, não seria possível saber qual deles teria sido "eleito" como competente. Os fatos, a depender de sua valoração, serviriam a justificar a fixação de competência em qualquer dos juízos em conflito.

Veja-se, que a partir do momento em que a Corte de Precedentes põe a "regra" e a “exceção", não define, em absoluto, a norma geral. Trocando em miúdos, o trecho acima colacionado nos diz basicamente o seguinte: a regra é do foro da capital, salvo se circunstâncias concretas justificarem que corra em outro juízo.

Ora, o raciocínio, caso aplicado em casos futuros, serviria para justificar qualquer decisão, fixando competência em qualquer juízo conflitante, a respeito de qualquer caso. É que o trecho da ementa pode ser utilizado como "precedente" favorável à regra ou à exceção, a depender do uso dado pelo intérprete. $\mathrm{E}$ foi exatamente isso que se deu no julgamento do $\mathrm{CC} \mathrm{n}^{\circ}$ 151.550/CE, proveniente também da Primeira Seção do STJ e cuja relatoria coube à Ministra Assusete Magalhães (DJE 20/05/2019). A ementa do CC n 144.922/MG foi citada e negritada, inclusive no tópico "17" acima colacionado.

Ocorre que o fundamento da decisão no $\mathrm{CC} \mathrm{n}^{\circ}$ 151.550/CE tomou por base a análise da prevenção do juízo para processamento de diversas ações civis públicas, enquanto o julgamento do $\mathrm{CC} \mathrm{n}^{\circ} 144.922 / \mathrm{MG}$ teve fundamentos distintos: as melhores condições de a $12^{\mathrm{a}}$ Vara Federal da Seção Judiciária de Minas Gerais dirimir as controvérsias relativas ao acidente ambiental. A questão cronológica serviu meramente como argumento de reforço, não sendo determinante (obiter dictum, nos parece) para a decisão.

Em suma, a ementa referenciada no $\mathrm{CC} \mathrm{n}^{\circ}$ 151.550/CE não foi extraída de julgado cujos fundamentos de fato e de direito foram semelhantes. Apenas o tema - definição da competência para julgamento de demandas coletivas - era o mesmo. O contexto fático e as razões de decidir foram, todavia, distintas. 
Trata-se, portanto, de referência simplesmente à ementa e não ao "precedente", cuja citação pode ser bastante nociva em um sistema como o consagrado no CPC, pois serve para fundamentar tudo, inclusive nada.

Pecamos bastante em referenciar ementas sem um aprofundado estudo das razões do voto vencedor. A cultura de ementário, aqui, demonstra a necessidade de compreender melhor como textualizar (=redigir preceitos normativos) e aplicar os precedentes.

\section{CONCLUSÃO - A FUNDAMENTAÇÃO COMO ELEMENTO CHAVE DO SISTEMA DE PRECEDENTES}

Tratamos, no tópico anterior, de um recorte. Apenas para demonstrar como a simples utilização da emente pode causar equívocos na aplicação dos precedentes judiciais. Por isso, a pergunta inicial a que nos propomos merece resposta negativa. Não parece que desenvolvemos um amadurecimento necessário para bem aplicar o nosso sistema de precedentes, conforme consagrado no CPC. Este amadurecimento, dentre diversos fatores, passa pela compreensão da função que a fundamentação das decisões judiciais exerce no processo.

Sempre que exerce seu poder-dever de julgar, impõe-se ao magistrado que fundamente sua decisão. Há, nesse sentido, norma constitucional inscrita no art. 93, IX, da CR e disposta da mesma forma no art. $489, \S 1^{\circ}$ do $\mathrm{CPC}$. Trata-se de elemento capaz de proporcionar legitimação à atividade jurisdicional ${ }^{10}$. "O Estado Democrático de Direito exige que o juiz motive racionalmente as suas decisões, combatendo toda e qualquer decisão baseada no intime conviction do magistrado" (CAMBI, 2011, p. 319) ${ }^{11}$.

O exercício da jurisdição impõe, pois, sejam motivadas as decisões.

O processo decisório, fruto da atividade jurisdicional, assume importante papel no modelo do formalismo-valorativo, funcionado em duas dimensões complementares: o juiz cria a

\footnotetext{
${ }^{9}$ Entre aspas, pois já deixamos claro que a nós não há como identificar uma ratio decidendi no julgamento do CC $\mathrm{n}^{\circ} 144.922 / \mathrm{MG}$.

10 "Mais importante, todavia, é a circunstância de a obrigação de fundamentar as decisões judiciais constituir um verdadeiro factor de legitimação do poder jurisdicional, contribuindo para a congruência entre o exercício desse poder e a base sobre a qual repousa: o dever de dizer o direito no caso concreto (iuris dicere). E, nessa medida, é garantia de respeito pelos princípios da legalidade, da independência do juiz e da imparcialidade das suas decisões" Tribunal Constitucional Português. Acórdão 680/1998. Relatora Maria dos Prazeres Pizarro Beleza. $2^{\circ}$ Secção. Disponível em: http://www.tribunalconstitucional.pt/tc/acordaos/19980680.html. Acesso: 09 set. 2020.

11 No mesmo sentido: MARINONI, 2013. pp. 413-417; LUCCA, 2015. p. 121-124. Noticia ainda Taruffo: “A concepção irracionalista do intime conviction é evidentemente incompatível com uma concepção epistêmica do processo: acaba por configurar e legitimar decisões puramente subjetivas, e, por conseguinte, substancialmente arbitrárias, do juiz de fato" (2012. p. 189).
} 
norma jurídica para o caso concreto, ao mesmo tempo em que cria também uma norma jurídica modelo para casos futuros semelhantes àquele.

O juiz, ao mesmo tempo em que assume, no processo democrático, a posição de sujeito do contraditório, deve propiciar um ambiente de diálogo que favoreça a tomada de uma decisão justa. Essa decisão não é aquela que somente faz justiça entre as partes envolvidas no litígio, possibilitando uma solução restrita ao caso concreto. A solução justa, objeto de uma prestação efetiva da jurisdição, é o ato final de um processo regido pelos princípios constitucionais e direitos fundamentais, que tendo proporcionado amplo debate, é capaz de servir como elemento de pacificação social, pois concretiza os valores do sistema processual constitucional vigente.

Considerando que da manifestação do órgão jurisdicional acerca de uma matéria pode se extrair norma individual e norma geral, adquire grande importância o processo de formação do entendimento do julgador. Este processo há de ser fruto de um diálogo cooperativo entre todos os sujeitos da relação processual, em vista daí ser obtida a justa decisão para o caso concreto. É esse processo comunicativo que legitima a atuação do juiz como representante estatal na solução do conflito e na consequente formação de uma norma geral aplicável a outros casos semelhantes.

Nesse processo de produção normativa, a fundamentação da decisão judicial é elemento chave. A própria Constituição exige sejam motivadas todas as decisões judiciais, sob pena de nulidade (art. 93, IX) ${ }^{12}$. Mais que isso, o dever de o magistrado expressar as razões de fato e de direito que lhe levaram ao convencimento decorre do Estado Democrático de Direito consagrado no art. $1^{\circ}$ da Carta $^{13}$, podendo-se afirmar direito fundamental do cidadão ${ }^{14}$. Assim, é possível

12 "A fundamentação das decisões judiciais tem tanta relevância no sistema que foi elevada à norma constitucional (art. 93, IX, da CF), que, ciente da gravidade do não cumprimento da regra constitucional, imputou, num inédito comando constitucional, a pecha de nula à decisão que não contiver a fundamentação. Esta é, repita-se, a única oportunidade na Constituição Federal em que é empregada a terminologia 'sob pena de nulidade"' (FERREIRA, 2014. p. 289).

13 "Fundamentar significa o magistrado das as razões, de fato e de direito, que o convenceram a decidir a questão daquela maneira. A fundamentação tem implicação substancial e não meramente formal, donde é lícito concluir que o juiz deve analisar as questões postas a seu julgamento, exteriorizando a base fundamental de sua decisão. Não se 'consideram substancialmente' fundamentadas as decisões que afirmam que, 'segundo os documentos e testemunhas ouvidas no processo, o autor tem razão, motivo por que julgou procedente o pedido'. Essa decisão é nula porque lhe falta fundamentação" (NERY JUNIOR, 2013. p. 301). No mesmo sentido: “A fundamentação é, em síntese, a justificativa pela qual se decidiu desta ou daquela maneira. É pois, condição de possibilidade de um elemento fundamental do Estado Democrático de Direito: a legitimidade da decisão. É onde se encontram os dois princípios centrais que conformam uma decisão: a integridade e a coerência, que se materializam a partir da tradição filtrada pela reconstrução linguística da cadeia normativa que envolve a querela sub judice" (MENDES; STRECK, 2013. p. 1325).

14“A fundamentação das decisões - o que, repita-se, inclui a motivação - mais do que exigência própria do Estado Democrático de Direito, é um direito fundamental do cidadão. Fundamentação significa não apenas explicitar o fundamento legal/constitucional da decisão. Todas as decisões devem estar justificadas e tal justificação deve ser feita a partir da invocação de razões e oferecimento de argumentos de caráter jurídico. O limite mais importante das decisões judiciais reside precisamente na necessidade de motivação/justificação do que foi dito. Trata-se de verdadeira 'blindagem' contra julgamentos arbitrários" (MENDES; STRECK, 2013. p. 1324). No mesmo sentido: 
entender que há um direito fundamental à motivação das decisões judiciais ${ }^{15}$, aspecto legitimador do processo de construção da norma jurídica apta a solucionar o caso concreto.

O dever de fundamentação das decisões judiciais não é um princípio, mas uma regra ${ }^{16}$ que impõe a demonstração das razões de decidir no caso concreto, servindo de garantia contra o $\operatorname{arbítrio~}^{17}$. O juiz, na fundamentação, faz um discurso com duas dimensões: a dimensão interna ao processo, vinculando as partes, e a dimensão externa, formando precedente sobre a matéria. Daí este dever servir ao complemento da função do contraditório no processo, como anota Marinoni (2013, p. 415):

Mas o contraditório, como mecanismo que garante a possibilidade de participação das partes, ainda que mediante alegações, provas etc., não é suficiente para garantir a legitimidade do processo jurisdicional. Para tanto, além da imprescindibilidade da publicidade dos atos do juiz, tem vital importância a fundamentação das suas decisões (...)

Tomam destaque, nesse ínterim, duas razões apontadas por Michele Taruffo (2011, pp. 333-343) e que fundamentam as normas impositivas do dever de motivação. A primeira dessas razões põe em evidência a obrigação de motivação perante as partes, evidenciada em tripla visão: a persuasão das partes (em especial a perdedora) quanto à justiça da decisão; maior facilidade para valoração da pertinência de impugnação, sendo possível identificar de modo mais preciso os vícios da sentença; a necessidade de que o conteúdo da decisão possa individualizar-se e se definir de modo adequado. A segunda razão diz respeito à facilitação do julgamento de eventual

"Hoje, qualquer ato processual, estatal ou não, deve ser racionalmente motivado. E, para os atos do Estado (não só do juiz), isso se torna ainda mais relevante porque a motivação das decisões vinculativas funda as conclusões tomadas não só no imperium que as caracteriza, mas sobretudo na racionalidade e coerência argumentativa da cognitio. $\mathrm{O}$ controle das decisões reclama que os atos do processo possam passar por testes argumentativos a partir da racionalidade, não só da conclusão ao final externada, mas também dos motivos que a fundamentam" (CABRAL, 2010. p. 142).

15 "No tenemos dudas que la motivación de las decisiones judiciales es un Derecho fundamental amparado en las constituciones que proscribe la arbitrariedad en las resoluciones judiciales y cumple el rol sustancial de legitimar la función jurisdiccional en la medida que vincula al juez a la supremacía constitucional, además se hace efectivo el control de la actividad jurisdiccional no solamente por parte del litigante, sino también por la sociedad" (MORALES, 2011. p. 347). Em tradução livre: "Não temos dúvidas que a motivação das decisões judiciais é um Direito fundamental amparado nas constituições que proíbe a arbitrariedade nas decisões judiciais e cumpre o papel substancial de legitimar a função jurisdicional na medida em que vincula o juiz à supremacia constitucional, além de tornar efetivo o o controle da atividade jurisdicional não apenas por parte do litigante, senão também pela sociedade".

16 Explica com acuidade Rodrigo Ramina de Lucca (2015, p. 80-88) que "Além de garantia, o dever de motivar as decisões judiciais é uma regra jurídica constitucional e processual, contida no devido processo legal e dele garantidora, que impõe a todo aquele que exerce o poder jurisdicional o dever de expor as razões de suas decisões, justificando-as formal e materialmente". O autor desenvolve, em um diálogo com a obra de Humberto Ávila, as razões do seu entendimento. Em sentido contrário, entendendo como princípio: CAMBI, 2011. p. 327.

17 "Essa exigência processual-constitucional de publicidade, racionalidade e fundamentação das decisões judiciais, como direito garantia fundamental de todo cidadão brasileiro, inegavelmente contribui para impedir que o Poder Judiciário possa proferir uma decisão única e exclusivamente baseada em critérios pessoais de justiça dos juízes, eis que objetiva despersonificação da decisão judicial, justamente para permitir a controlabilidade jurídica e crítica da decisão pelas partes e pelos demais cidadão interessados.” (MORAIS, 2011, p. 138-139). 
impugnação pelo órgão competente, pois, assim como para as partes, é a fundamentação da decisão que permite ao juízo ad quem observar as motivações de manutenção ou reforma da decisão. Denota-se, assim, que a motivação da decisão judicial reverbera para além do grau de jurisdição donde se prolata.

É essa motivação que permite aos sujeitos do processo exercerem a faculdade de recorrer das decisões a si prejudiciais, não podendo haver limitação em virtude de ausência de fundamentação da decisão. A motivação da sentença permite verificar a utilidade do recurso, viabilizando a compreensão das razões que levaram àquela decisão e, assim, a elaboração consciente das razões recursais (NOJIRI, 1998, p. 29-32). A falta de fundamentação constitui óbice à impugnação da decisão. A norma jurídica do caso concreto, pois, somente pode ser interpretada caso a fundamentação para a tomada de decisão seja posta.

Doutro modo, identifica-se também uma função extraprocessual, na medida em que reverbera para além do processo o entendimento judicial consignado, dando publicidade a todos das razões que levaram à decisão. Além disso, a publicidade da fundamentação autoriza um controle político e democrático da jurisdição ${ }^{18}$.

São essas razões que permitem, num processo hermenêutico, construir a norma geral conformadora do precedente e a norma concreta que regula a situação submetida à apreciação judicial. É a própria fundamentação das decisões que gera o precedente e a solução ao caso concreto submetido à jurisdição.

Em suma, "O dever de motivação exerce, pois, uma função endoprocessual, consistente em facilitar a impugnação por intermédio dos recursos. (...) também possui uma função extraprocessual, qual seja, servir de controle democrático do exercício do poder" (CAMBI, 2011, p. 338).

A fundamentação, ao fim e ao cabo, "constituye uns exposición del razonamiento justificativo de las bases en las quales se fundamenta la decisión judicial" (MORALES, 2011, p. 352). O dever de fundamentação das decisões judiciais exerce papel de destaque no processo, especialmente quando pensamos na construção de um sistema de precedentes. A motivação da decisão judicial é necessária à sua própria legitimação dentro da ordem jurídica como fonte de norma jurídica. "Pode-se ser mais direto: sem motivação não há qualquer possibilidade de

18 Sobre a função extraprocessual da motivação, apresentando um pano de fundo histórico: SANTOS, 2011, p. 158159). 
processo justo" (LANES, 2011, p. 199), não há qualquer possibilidade de estruturação de um sistema de precedentes.

Todos os conceitos fundamentais que tratamos estão intimamente ligados à fundamentação das decisões. Sem fundamentação adequada, pouco se pode acrescentar na compreensão do que é ratio decidendi e obiter dictum, do que é mesmo precedente, de como identificar o entendimento da jurisprudência e como redigir bem seus enunciados. Não basta teorizar. No caso concreto, o retorno é à decisão, aos seus fundamentos.

A cultura do ementário prejudica a consolidação e o amadurecimento do sistema de precedentes no Brasil. Necessário, portanto, amadurecer as compreensões e a forma de lidar com os precedentes. O caminho da mudança não é fácil, mas temos as ferramentas à nossa disposição. Precisamos aprender a trabalhar com elas.

\section{REFERÊNCIAS BIBLIOGRÁFICAS}

CABRAL, Antonio do Passo. Nulidades no processo moderno: contraditório, proteção da confiança e validade prima facie dos atos processuais. Rio de Janeiro: Forense, 2010.

CAMBI, Eduardo. Neoconstitucionalismo e neoprocessualismo: direitos fundamentais, políticas públicas e protagonismo do judiciário. São Paulo: RT, 2011.

CUNHA, Leonardo Carneiro da. O processo civil no estado constitucional e os fundamentos do projeto do novo código de processo civil. Repro, São Paulo, v. 209, 2012.

DIDIER Jr., Fredie. BRAGA, Paula Sarno; OLIVEIRA, Rafael. Curso de Direito Processual Civil. Salvador: Jus Podivm, 2014. v. 2.

DUXBURY, Neil. The Nature and Authority of Precedent. Cambridge University Press, 2008.

FERREIRA, William Santos. Princípios fundamentais da prova cível. São Paulo: RT, 2014.

GOODHART, Arthur L. Determining the Ratio Decidendi of a Case. The Yale Law Journal, v. 40, n. 2, p. 161-183, dec. 1930. Disponível em: http://www.jstor.org/stable/790205 .

JUSTO, A. Santos. Direito Privado Romano: 1. Coimbra: Coimbra Editora, 2008.

LANES, Júlio Cesar Goulart. Fato e direito no processo civil cooperativo. São Paulo: RT, 2014.

LUCCA, Rodrigo Ramina de. O dever de motivação das decisões judiciais. Salvador, JusPodvm, 2015. 
MACEDO, Lucas Buril de; PEREIRA, Mateus Costa; PEIXOTO, Ravi de Medeiros. Precedentes, cooperação e fundamentação: construção, imbricação e releitura. O projeto do novo código de processo civil. ADONIAS, Antônio; DIDIER JR., Fredie (org.). Salvador: Jus Podivm, 2012.

MACEDO, Lucas Buril de; PEREIRA, Mateus Costa; PEIXOTO, Ravi de Medeiros. Precedentes judiciais e o direito processual civil. Salvador: JusPodivm, 2016.

MARINONI, Luiz Guilherme. Precedentes Obrigatórios. São Paulo: RT, 2010.

MARINONI, Luiz Guilherme. O Precedente na Dimensão da Segurança Jurídica. In: MARINONI, Luiz Guilherme (org.). A força dos precedentes. Salvador: JusPodivm, 2012.

MARINONI, Luiz Guilherme. Elaboração dos conceitos de ratio decidendi (fundamentos determinantes da decisão) e obiter dictum no direito brasileiro. In: MARINONI, Luiz Guilherme (org.). A força dos precedentes. Salvador: JusPodivm, 2012.

MARINONI, Luiz Guilherme. Luiz Guilherme. Teoria Geral do Processo. São Paulo: RT, 2013.

MENDES, Gilmar Ferreira; COELHO, Inocêncio Martins; BRANCO, Paulo Gustavo Gonet Curso de direito constitucional. São Paulo: Saraiva, 2007.

MENDES, Gilmar Ferreira; COELHO, Inocêncio Martins; BRANCO, Paulo Gustavo Gonet; STRECK, Lenio Luiz. Comentário ao art. 93. In: CANOTILHO, J. J. Gomes; SARLET, Ingo W. Comentários à Constituição do Brasil. São Paulo: Saraiva/Almedina, 2013.

MORAIS, Dalton Santos. Democracia e Direitos fundamentais: Proposta para uma Jurisdição Constitucional Democrática. In: FELLET, André; NOVELINO, Marcelo (org.). Constitucionalismo e Democracia. Salvador: JusPodivm, 2013.

MORALES, Rodrigo Rivera. La Prueba: un análisis racional y práctico. Madrid: Marcial Pons, 2011.

NERY JUNIOR, Nelson. Princípios do Processo na Constituição Federal. São Paulo: RT, 2013

NOGUEIRA, Gustavo Santana. Precedentes vinculantes no direito comparado e brasileiro. Salvador: JusPodivm, 2012.

NOJIRI, Sérgio. O dever de fundamentar as decisões judiciais. São Paulo: RT, 1998. 
PEIXOTO, Ravi. Superação do precedente e segurança jurídica. Salvador: JusPodivm, 2015.

SANTOS, Tomás-Javier Aliste. La motivación de las resoluciones judiciales. Madrid-ES: Marcial Pons, 2011,

SARLET, Ingo; MARINONI, Luiz Guilherme; MITIDIERO, Daniel. Curso de Direito Constitucional. São Paulo: RT, 2012.

TARUFFO, Michele. La motivación de La sentencia civil. Madri: Editorial Trotta, 2011.

TARUFFO, Michele. Uma simples verdade: O Juiz e a construção dos fatos. São Paulo: Marcial Pons, 2012.

TORRES, Heleno Taveira. Direito Constitucional Tributário e Segurança Jurídica. São Paulo: RT, 2011.

TUCCI, Rogério Cruz e. Precedentes Judiciais como fonte do direito. São Paulo: RT, 2004.

WAMBAUGH, Eugene. The study of cases: a course for instruction in reading and stating reported cases, composing head-notes and briefs, criticizing and comparing authorities, and compiling digests. Bostom: Little, Brown \& Co., 1892. 